RoBinow, C. F. (1951). J. gen. Microbiol. 5, 439-457.

\title{
Observations on the Structure of Bacillus Spores
}

\author{
By C. F. ROBINOW \\ Department of Bacteriology and Immunology, University of \\ Western Ontario, London, Ontario, Canada
}

SUMMARY: An internal organization is revealed in resting spores of Bacillus spp. by brief treatment at room temperature with $\mathrm{N}-\mathrm{HNO}_{3}$ or, more effectively, a mixture of $\mathrm{N} / 3-\mathrm{HNO}_{3}$ (or $\mathbf{H C l}$ ) with $0.1 \%$ potassium permanganate. Two distinct steps are involved: the first initiates the reaction without visible changes in the spore; the second is an instantaneous process which abolishes the refractility of the spore and allows staining of the contents. These differentiating procedures have no observable effect on vegetative cells, and the spore's response to them is abruptly abolished with the onset of germination. They are ineffective on heat-killed spores and are inhibited, under certain conditions irreversibly, by 0.5-1\% sodium fluoride. Differentiating reagents probably act indirectly by stimulating abnormal chemical activity of the spore.

Three structures, interpreted as the outer spore membrane, nucleus and cytoplasm, can be distinguished in treated spores. Differentiation does not alter the size or the shape of the spore but shrinks the cytoplasm away from the membrane and, in permanganate-containing mixtures, changes the configuration of the nucleus. The extent of these rearrangements varies with the temperature at which differentiation is carried out. The nucleus is on the outer surface of the cytoplasm and connected with it by a short narrow stalk. The nucleus gives a positive Feulgen reaction. Nucleus and cytoplasm of spores differentiated with $\mathrm{N} / 3-\mathrm{HNO}_{3}$ or $\mathbf{H C l}$ containing $0 \cdot 1 \%$ of $\mathrm{KMnO}_{4}$ are soluble in phosphate buffers at $\mathrm{pH} \mathrm{6.3-7 \cdot 6}$ and $\mathrm{M} / 16$ sodium acetate at $\mathrm{pH} \mathbf{7 \cdot 4}$. Nucleus and cytoplasm are insoluble in these solutions after differentiation with $\mathrm{N}-\mathrm{HNO}_{3}$, but the nucleus of spores treated in this way is destroyed by trypsin in phosphate buffer.

The existence of a second, inner, spore membrane, jointly surrounding nucleus and cytoplasm, is postulated. This layer is believed to be the seat of the spore's bright refractility and imperviousness to stains.

The huge spores of Metabacterium polyspora react like Bacillus spores to differentiating reagents and permit direct observation of the act of transformation from the featureless to the differentiated aspect of the spore.

A curiously organized cell is concealed beneath the smooth, featureless, noncommittal exterior of the bacterial spore. Two kinds of description of the structure of this cell have been given in the last 15 years. Milovidov (1935), Stille (1937), Delaporte (1939-40) and Piekarski (1940) noted a Feulgen-positive rodlet or granule in the periphery of the spore, but remained silent on the configuration of the interior of the cell. It was eventually realized that after acid hydrolysis at $60^{\circ}$ the Feulgen-positive element of the cell is visible as a bright, colourless object at the periphery of the normally featureless spore, and that for the general description of the spore Schiff's reagent could, with advantage, be replaced by staining with ordinary dyes. Accounts of spore structure based on this technique-successfully employed in the study of vegetative forms by Piekarski (1937)-have been given by Robinow (1942, 1945), Klieneberger-Nobel (1945), Flewett (1948), Delaporte (1950), and 
Bisset (1950). The newer descriptions have confirmed the presence of a chromatinic structure close to the surface of the resting spore and have provided information on the hitherto undescribed cytoplasmic portion of the cell.

In previous papers (Robinow, 1942, 1945) the cytoplasm was described as occupying most of the space within the spore, separate from the peripheral chromatinic body or nucleus, and differentiated into a basophilic Feulgennegative core, surrounded by a layer of poorly stainable material. New observations, described in the present paper, have led to a revision of this interpretation. The 'core' is now recognized as the whole of the more or less extensively shrunken cytoplasm, and the clear layer surrounding it as the space between the collapsed cytoplasm and the membrane. New information on the structure of the nucleus and its relation to the cytoplasm has also been obtained.

\section{EXPERIMENTAL}

\section{Materials}

Bacillus cereus and its variants, because of the large size of its spores and the abundance with which they are formed on ordinary media, has been the chief subject of this study. The strain mainly used was identified by the egg-yolk reaction of McGaughey \& Chu (1948) and morphologically. It was originally received from Dr T. F. Flewett as a motile, avirulent variant of $B$. anthracis. $B$. cereus var. mycoides and ' $B$. mycoides 1110', a smooth cereus culture described by den Dooren de Jong (1933), were included among the cereus strains. Spores of B. subtilis, B. megatherium, B. pumilus, B. sphaericus and $B$. polymyxa were also examined.

In cytological studies on spores the simultaneous presence of different developmental stages and of disintegrating vegetative forms increases the difficulties of interpretation, and only cultures in which mature spores readily become predominant are really useful. Most of the Bacillus cultures used in the present study attained this condition after 2 or 3 days at $37^{\circ}$ on a simple potato extract agar. (The potato extract is prepared by boiling $200 \mathrm{~g}$. of peeled and chipped potatoes for $20 \mathrm{~min}$. in 1 l. of tap water. The decoction is made up to its original volume and filtered through cotton, $1.5 \%$ agar is added and the $\mathrm{pH}$ adjusted to $7 \cdot 6$.)

Spores of Metabacterium polyspora (Chatton \& Pérard, 1913) from the caecum of guinea-pigs, where they were often found in large numbers, have been examined for comparison with Bacillus spores.

\section{Methods of differentiation}

Thin films of spores from slope cultures were made in distilled water on grease-free cover-slips and allowed to dry in air. The results obtained with living and fixed spores were identical. For this reason fixatives were not used in this study, except when stated in the text.

The new and very simple methods employed in this study are based on the observation that $\mathrm{N}-\mathrm{HCl}$ exerts its differentiating effect on spores at room temperature (Robinow, 1945). Higher temperatures are not necessary and 
damage nucleus and cytoplasm. Later, $\mathrm{N}-\mathrm{HNO}_{3}$ was found to be an even more useful agent. Equivalent concentrations of $\mathrm{HNO}_{3}$ and $\mathrm{HCl}$ affect spores differently. $\mathrm{N}-\mathrm{HCl}$ and $\mathrm{N}-\mathrm{HNO}_{3}$ are active at room temperature, $\mathrm{HNO}_{3}$ acting considerably faster than $\mathrm{HCl}$, but only $\mathrm{HNO}_{3}$ is also active at $\mathrm{N} / 3$ at this temperature. Sulphuric acid, surprisingly, proved entirely ineffective over a wide range of concentrations at different temperatures, and $\mathrm{N}-\mathrm{NaOH}$ likewise had no effect.

The method that was most useful was arrived at unexpectedly. It was found that $1 \%$ potassium permanganate in $c . \mathrm{N} / 3-\mathrm{HCl}$ (a powerful spore disinfectant according to Kroenig \& Paul, 1897) not only killed spores with great rapidity, but, at the same time, caused differentiation, which had not been expected to occur before subsequent treatment with acid. Applied for 5-10 min. at room temperature, $\mathrm{N} / \mathbf{3}-\mathrm{HCl}$ by itself has a negligible, and $1 \%$ permanganate no noticeable, effect on the morphology and viability of the spores examined. The following differentiating methods were used before staining:

Method 1. $\mathrm{N}-\mathrm{HNO}_{3}$ for $10 \mathrm{~min}$. at room temperature.

Method 2. Potassium permanganate $(0 \cdot 1 \%)$ in $\mathrm{N} / 3-\mathrm{HNO}_{3}$ for $5-10 \mathrm{~min}$. at room temperature. The reagent was prepared by mixing 2 vol. $0 \cdot 15 \%$ potassium permanganate with 1 vol. of $\mathrm{N}$ acid; it proved fairly stable and retained its activity for many hours.

Method 3. Potassium permanganate $(0 \cdot 1 \%)$ in $\mathrm{N} / 3-\mathrm{HCl}$. Mixtures of permanganate with $\mathrm{HCl}$ are unstable. Spore films were either treated for $10 \mathrm{~min}$. with freshly prepared solution as in method 2 , or the mixture was first allowed to 'ripen' for $\mathbf{3 0} \mathrm{min}$. and then applied for $5 \mathrm{~min}$.

All three methods give excellent results with cereus spores, but method I proved more satisfactory than methods 2 and 3 for spores of $\boldsymbol{B}$. subtilis and $B$. megatherium. Treated films were rinsed several times with distilled water and dried for 1-2 min. while standing on a piece of blotting-paper in the $37^{\circ}$ incubator. Unless they had been dried, most of the spores became partly detached from the cover-slip and, in wet mounts, exhibited Brownian motion.

Staining was carried out as follows:

(1) Crystal violet $(0.01 \%)$ in water was used throughout. The period of staining varied with the pre-treatment: $0 \cdot 5-1 \mathrm{~min}$. sufficed after permanganate$\mathrm{HCl}$; 2-3 min. were required after pre-treatments involving nitric acid. Giemsa solution was used occasionally and gave clear and brilliant pictures.

(2) Feulgen test. Unfixed spores were hydrolysed in $\mathrm{N}-\mathrm{HCl}$ at $60^{\circ}$ for 10-12 min. and then treated with Schiff's reagent for several hours. No counterstain was used.

(3) Preparations made by the osmium-HCl-Giemsa method (Robinow, 1942, 1945) were examined for comparison with the results of differentiating methods 1,2 and 3.

All pre-treatments and staining were carried out in 'Columbia' staining dishes for cover-slips (A. H. Thomas Company, Philadelphia), which were found more convenient than watch-glasses for the simultaneous processing of groups of spore films. All preparations were examined mounted in water, and were sealed with paraffin. For optical equipment see Robinow (1942). A green 
light-filter, either Zeiss 'trichrome' or Wratten B 58, was always used. A red filter, Wratten F29, proved helpful in resolving the structure of nuclei too deeply stained to be transparent in illumination with green light.

\section{RESULTS}

Appearance of normal resting spores of Bacillus cereus

Spores of $B$. cereus are shrouded in a tenuous, ballooning envelope which in some strains protrudes considerably over the ends of the cell (PI. 1, fig. 1). This 'exosporium' (Lewis, 1934) is plainly visible in suitably stained preparations and invariably in electron-micrographs of cereus spores (Pl. 3, figs. 17, 18 and 20), and is quite distinct from the spore membrane proper. The spores differ greatly in size, are brightly refractile and have a faint brownish tint. As a rule no detail of the interior is visible in viable resting spores of $\boldsymbol{B}$. cereus and other bacilli, and none is revealed by straightforward staining, or phasecontrast microscopy.

\section{Internal structure of resting spores of Bacillus cereus}

None of the three principal differentiating methods used is without disadvantages. However, the picture of spore structure they furnish between them is consistent and plausible. The configuration and response to differentiating procedures of nucleus, cytoplasm and spore membrane will now be discussed separately.

\section{The nucleus}

All differentiating methods reveal a chromatinic structure, interpreted as the nucleus, at the periphery of the cell (Pls. 1, 2, 4 and 5). The shape of this body depends on the method used and, to some extent, on the temperature at which differentiation is carried out. Although there is a good deal of overlap between the results of the various treatments they are sufficiently different to warrant separate description.

The nucleus of most spores differentiated by $\mathrm{HNO}_{3}$ at room temperature appears in side view as a band of chromatin of uneven density which follows the contours of the cell on one side and frequently curves around one of the poles as well (Fig. 1 $a$; Pl. 1, figs. 4, 5). The thinnest nuclei and those best fitting into the normal shape of the spore are seen when differentiation is carried out in the refrigerator at $4-6^{\circ}$ (Fig. 2). Seen from the surface, the nucleus appears ovoid or circular. Often its shape is not entirely symmetrical and its edge, where it runs across the surface of the cell, is cut off more or less squarely (Pl. 1, fig. 6) or at an angle or is slightly dented.

Mixtures of permanganate with $\mathrm{N} / 3-\mathrm{HNO}_{3}$ or $\mathrm{N} / 3-\mathrm{HCl}$ cause the nuclei to become more or less rounded (Pl. 2). In their changed shape the nuclei cannot be accommodated within the normal confines of the spore and project above the cell surface (Fig. $1 b ; \mathrm{Pl}$. 2, figs. 8, 11 $b, 12 b, 13 b$ ). An advantage of this kind of preparation is the clarity with which the nucleus is revealed as a threedimensional structure. The nuclei appear to possess a shell of dense chromatinic matter surrounding a lighter centre, especially when they are viewed in red light 
(Pl. 4, fig. 26). Vesicles, partly flattened spheres, circular and semicircular disks are the predominant shapes, but since most of the chromatin is in the margin, the immediate impression given by these configurations in lightly stained films is that of rings or crescents. Spores which have become detached from the cover-slip in wet mounts and are tumbling over in Brownian movement allow one to catch a glimpse of the same nucleus from different angles. In this
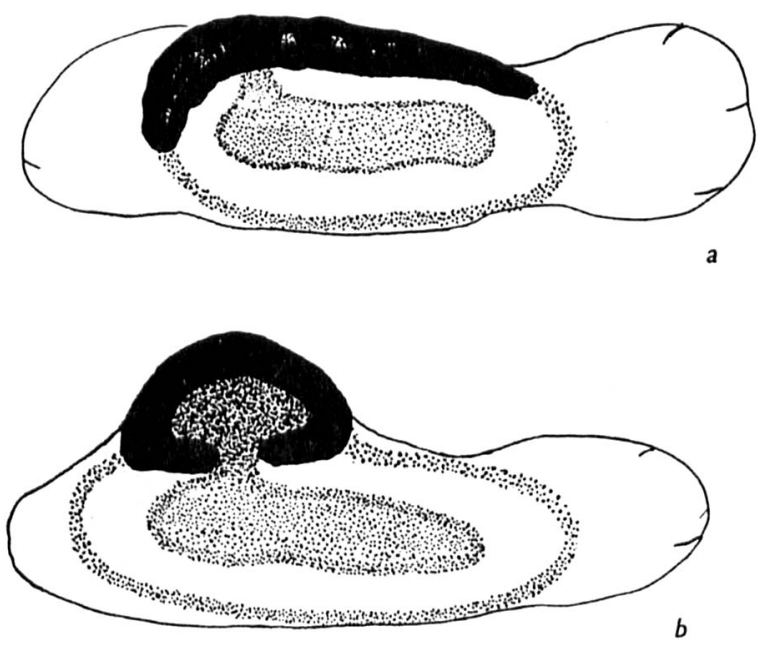

Fig. 1. Diagrammatical longitudinal optical section showing the salient features of spores of $B$. cereus differentiated by method 1, above, and methods 2 or 3 below. The spores are shrouded in a delicate envelope which projects beyond the poles of the cell. The nucleus, the dense structure at the surface of the cell, is connected by a narrow stalk with the central body of shrunken spore cytoplasm. The spore membrane is shown as a stippled band, drawn relatively too wide to conform with the imperfectly resolved image of the membrane in the light microscope. The relationship of the spore membrane to the nucleus, still being a matter of doubt, has been left undetermined.

way the 'curved rodlet' type of nucleus described in the past, is readily identified as the lateral aspect of the disk or vesicle configuration. The nuclei are compact and extend over not more than one-half to one-third of the length of the spore. Their contours are remarkably smooth (more so than after differentiation by method 1) and sharply defined (Pl. 3, figs. 19, 20).

The nuclei of cereus spores differentiated by $\mathrm{HNO}_{3}$ are destroyed by $25-50 \mu \mathrm{g}$. twice-crystallized trypsin (Worthington Biochemical Laboratories, Freehold, New Jersey, U.S.A.)/ml. $\mathrm{m} / 15$ phosphate buffer at $\mathrm{pH} 7 \cdot 8$ in $15 \mathrm{~min}$. at room temperature (Pl. 4, fig. 27), but not by trypsin in water.

No effect on the nucleus was noted after digestion with crystallized pepsin (Armour and Co.) at $\mathrm{pH} \mathrm{2.0} \mathrm{in} \mathrm{concentrations} \mathrm{varying} \mathrm{from} 30$ to $200 \mu \mathrm{g} . / \mathrm{ml}$. at room temperature. Crystalline deoxyribonuclease(Worthington Biochemical Laboratories) weakened, but did not entirely abolish the normally very distinct positive Feulgen reaction of the nuclei. The spores were first hydrolysed at $60^{\circ}$ with $\mathrm{N}-\mathrm{HCl}$ to make the nuclei accessible and then digested in distilled water for $0.5-1.5 \mathrm{hr}$. with $200-330 \mu \mathrm{g}$. enzyme $/ \mathrm{ml}$. in presence of a trace of 
magnesium chloride. The distinctness of the Feulgen reaction of controls incubated in distilled water was not impaired.

\section{The cytoplasm}

Regardless of the differentiating method used, part of the interior of the spore is invariably occupied by a centrally placed mass of basophilic matter, cast more or less in the shape of the spore but having a much smaller volume. The central body is more sharply defined in spores treated with

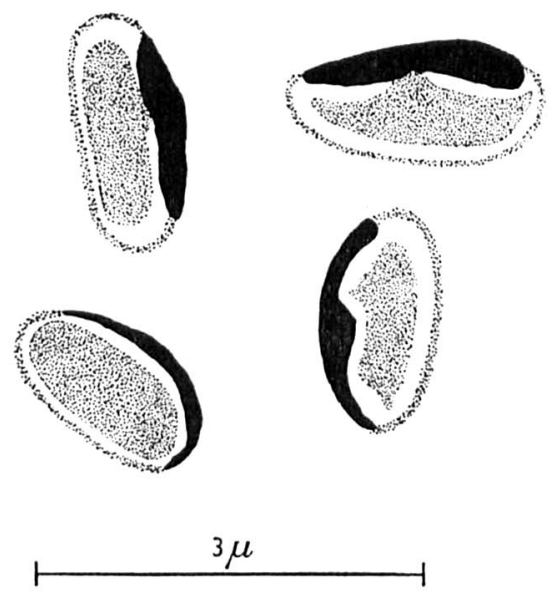

Fig. 2

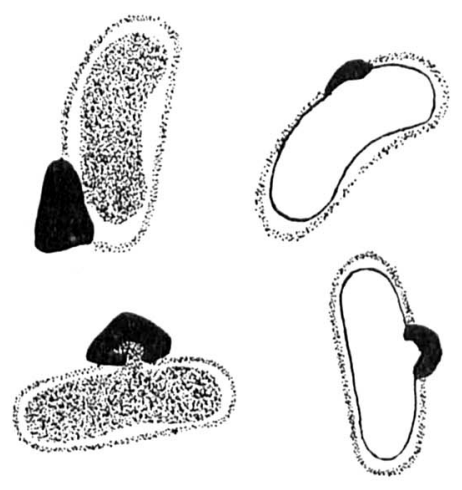

Fig. 3

Fig. 2. Spores of $B$. cereus, from a preparation that had been differentiated for $10 \mathrm{~min}$. with $\mathrm{N}-\mathrm{HNO}_{3}$ at $6^{\circ} \mathrm{C}$. The outer spore envelope has been omitted. Explanation in the text.

Fig. 3. Spores of $B$. cereus from a preparation differentiated for $10 \mathrm{~min}$. with $\mathrm{N} / 3-\mathrm{HCl}$ containing $0 \cdot 1 \% \mathrm{KMnO}_{4}$ at $6^{\circ} \mathrm{C}$. The outer spore envelope has been omitted. The central body in the two spores on the right was brightly refractile and only faintly stained. Explanation in the text.

permanganate mixtures than in spores differentiated with the aid of plain $\mathrm{HNO}_{3}$ or $\mathrm{HCl}$. Its size depends markedly on the temperature at which differentiation is carried out. The central mass is relatively large and shows but slight deviation from the proportions of the intact spore when differentiation is carried out in the cold $\left(4-6^{\circ}\right)$ (Figs. 2, 3). Under these conditions when differentiation is by method 3 the central body often appears glossy and is poorly stainable (Fig. 3), indicating that not the spore membrane, but rather the surface of the spore contents is brightly refractile and impervious to stains.

The central body in spores differentiated at room temperature is relatively small and slender (Fig. 1b). Somewhere along its side, usually near the middle, there may be continuity between the central body and the nucleus in the shape of a broad neck or short, narrow stalk. This is commonly seen in spores treated by methods 2 or 3 ; less distinctly or not at all in spores differentiated by method 1 . The destruction of the nucleus by trypsin is accompanied by more or less extensive shrinkage of the central body (Pl. 4, fig. 27).

This picture of spore structures, illustrated in Figs. 1 and 2, has formerly been interpreted by the writer to mean that the cytoplasm of the spore is 
differentiated into two regions: a basophilic core and a clear poorly stainable outer layer, the whole imagined to be surrounded by a closely fitting and invisible membrane (Robinow, 1945). It now seems more likely that the basophilic core is the remains of the spore's cytoplasm after a process of shrinkage or collapse, and the clear outer region is a free space between the contracted cytoplasm and the more rigid spore membrane.

The new interpretation is partly based on observations on the spores of Metabacterium polyspora. Metabacterium is an actively motile, peritrichously flagellated organism distinguished by unusual size and the ability to form up to nine spores in one cell. The problem of its cultivation has not yet been solved and its mode of reproduction is uncertain. The length of Metabacterium spores varies from 7 to $11 \mu$. Their width is about $2 \mu$ (Pl. 1, fig. 7; Pl. 3, fig. 14a). Treatment by methods 1, 2 or 3 has the same differentiating effect on these spores as on spores of bacilli, and the interior of the huge cells resembles, on an enlarged scale, the picture of cereus spores.

The large size of the Metabacterium cells allows the process of differentiation to be followed under the microscope, and enables the observer to form a threedimensional picture of the shapes that emerge. The transformation of the radially symmetrical, smooth, featureless and brightly shining spores into the oddly shaped transparent structures shown in Pl. 3, figs. 14b, 15, has repeatedly been observed: it takes place very suddenly and without warning after the spores have been in contact for several minutes with the differentiating reagent. The spore substance seemed to contract away from the poles of the cell. The configuration of the interior found after treatment with $\mathrm{HNO}_{3}$ is shown in $\mathrm{Pl}$. 3, figs. $14 b, 15$, and may be described as a hollow disk or domed button arising from the side of a more or less cylindrical, longer part. The latter tapers towards the ends and often shows a distinct constriction opposite the point where, mushroom-like, the peripheral disk arises on a short stalk. Contraction of the contents of Metabacterium spores is slight or may be absent when differentiation by methods 1 or 3 is carried out in the cold.

In Metabacterium the collapse of the central body can actually be seen taking place. In Bacillus cereus, after the same treatment, a similarly shaped body is found, and it seems plausible to assume that there is a similar collapse. The observation that in both species the size of the central body varies with the temperature of the differentiating agent also argues in favour of this view. Lastly, it is supported by evidence from electron-micrographs of differentiated Bacillus spores which show a dense core, i.e. the collapsed central body, surrounded, at some distance, by a delicate membrane (Pl. 3, figs. 19, 20; Pl. 6, figs. 32, 33).

In cereus spores differentiation has also been followed under the microscope many times, but the small size of the spores and the instantaneous nature of the transformation jointly defeated all attempts to distinguish consecutive steps of the process.

Solubility of nucleus and cytoplasm in phosphate buffer. Experiments with salt solutions, serving as controls to treatments with enzymes, revealed that after differentiation by method 2 the spore nucleus is destroyed and the central body 
reduced to a mere thread or completely dissolved by $\mathrm{m} / 15$ phosphate buffer at $\mathrm{pH} 6 \cdot 3-7 \cdot 6$ or by $\mathrm{m} / 16$ sodium acetate at $\mathrm{pH} 7 \cdot 4$. Nuclei and cytoplasm of spores differentiated with $\mathrm{N}-\mathrm{HNO}_{3}(\operatorname{method} 1)$ proved insoluble or only slightly soluble in these reagents. This procedure was therefore chosen to prepare spores for digestion with trypsin in phosphate buffer.

Effect of Feulgen hydrolysis on nucleus and cytoplasm. Treatment with $\mathrm{N}-\mathrm{HCl}$ at $60^{\circ}$ now appears more complex than mere hydrolysis. The acid acts first as a differentiating agent and then exerts a hydrolysing effect on the structures which differentiation has rendered accessible. After Feulgen hydrolysis, especially after fixation with osmium tetroxide, the central body is ill-defined and less basophilic than after differentiation at room temperature (Pl. 4, figs. 24, 25). Spores so treated tend to stain evenly all over (cf. Pl. IV, fig. 23 in Robinow, 1945) either because of the accumulation of stainable matter in the space between the much-diminished central body and the spore membrane or because of greater stainability of the membrane itself.

Sometimes the nuclei appear broken up into two or three granules or rodlets or combinations of these (Pl. 4, figs. 24, 25). Arrangements resembling four granules grouped like the 4 on a dice, or three granules arranged in V-shape are common under these conditions in $B$. cereus and $B$. cereus var. mycoides where they have been seen by Robinow (1942) and Delaporte (1950). Change of focus reveals in many cases that the rodlets and granules are connected, and it is then easily seen that these clusters are modified ring forms. It is interesting to note that very similar configurations form the chromatinic structures of the vegetative forms of $B$. cereus (Robinow, 1942), where osmium tetroxide causes similar changes in configuration. The loss of a clear view of the cytoplasm caused by Feulgen hydrolysis is thus offset by the demonstration of separate parts in the nucleus, and sharper differentiation of nucleus and cytoplasm than is achieved by more gentle methods of differentiation. It should be remembered, however, that this disjointed aspect of the nucleus is an artefact and that normally its parts are continuous.

A clear-cut Feulgen reaction is given by the basophilic shell of the nucleus (Pl. 4, figs. 21-23). In wet mounts it appears that the central, shrunken body of cytoplasm and the spore membrane also give a positive reaction. However, when the spores are dehydrated with ethanol and embedded in Canada balsam, the magenta colour of the nuclei is intensified, and spore membrane and cytoplasm are no longer visible, in agreement with the results of most of the earlier workers. This suggests that the positive reaction of cytoplasm and spore membrane in water mounts is an optical illusion, due to an unspecific faint reddish tinge, reinforced by the relatively high refractive index of these structures. A final decision is difficult because much of the cytoplasm is lost from the spores in the course of Feulgen hydrolysis.

\section{The spore membrane}

One might attribute the striking transformation of the appearance of resting spores, caused by differentiating agents, to drastic changes in the spore coat. But the spore membrane is not impervious to stains, even in the untreated 
resting spore. This is apparent from the tinted contours and dimmed refractility of spores stained with crystal violet (Pl. 2, fig. 11 a). Secondly, the spore coat which is discarded during germination is not noticeably affected by the reagents used in differentiation. Thirdly, differentiation by method 3 in the cold causes the separation of contents and membrane, and reveals that refractility and poor affinity for stains are properties of the cytoplasm rather than of the membrane (Fig. 3). These facts point to the interior of the spore as the site of the striking changes wrought by differentiating procedures. Any changes in the spore membrane may simply be the consequence of its separation from the normally impervious, refractile central body, or may be due to an increase in thickness.

So far it has not been possible to decide whether nuclei which protrude above the cell surface merely lift and stretch the spore membrane, or have actually burst through. It is likely that the electron microscopy of differentiated spores whose nuclei have been removed with salt solutions will be helpful in solving this problem. Meanwhile, the ability of the spore membrane to withstand stretching without rupture is evident from the conspicuous humps, caused by underlying rounded nuclei (Pl. 1, figs. 1-3), which arise in the otherwise normal-looking spore surface when certain concentrations of chlorine water or hypochlorite (see below) are used instead of permanganate in differentiation by method 3. Comparison of Pl. 2, fig. $11 a$ with fig. $11 b$, when the unnaturally protruding nuclei are disregarded, reveals that size and shape of the volume enclosed by the spore membrane are little changed by differentiation. This implies a certain rigidity of the membrane, at least in the wet state. On the other hand, the drying which is unavoidable in preparing cells for electron microscopy leaves the membrane of eereus spores in a much folded and shrivelled condition ( $\mathrm{Pl} .3$, figs. 19, 20).

Structure of the spores of Bacillus subtilis and Bacillus megatherium

While Bacillus spores differ as regards size and shape of the nucleus and relative size of nucleus and cytoplasm, spores of $B$. sphaericus, $B$. polymyxa, $B$. pumilis and $B$. cereus var. mycoides respond to differentiating treatments in very similar fashion. The structure of the spores of $B$. megatherium and B. subtilis, in contrast to cereus spores, varies little with the temperature and nature of the differentiating agent. Nitric acid (N) at room temperature (method 1) has proved most satisfactory.

B. subtilis. The spores of four strains examined have, in the differentiated condition, a certain neatness and uniformity of appearance. Compact rounded nuclei that project above the cell surface are most commonly seen (PI. 5, figs. 28, 29; Pl. 6, figs. 32-34). Thin flat nuclei that follow the contours of the spores, recalling those found in $B$. cereus after differentiation with $\mathrm{N}-\mathrm{HNO}_{3}$, are common after very brief treatment or when differentiation has been carried out in the cold. Electron micrographs (which the author owes to the kindness of Dr C. G. Hedén, of the Karolinska Institute, Stockholm) show the membrane remarkably free from folds, the shrunken cytoplasm, and dense angular nuclei. It is tempting to speculate whether a shallow depression in the cytoplasm of 
some of the spores in $\mathrm{Pl} .6$, fig. 34, corresponds to the site occupied by the nucleus in the untreated cell before differentiation caused a drastic change in its shape, but it is difficult to judge how much the configuration of the cytoplasm has been influenced by the drying to which cells are unavoidably subjected in electron-microscopy.

B. megatherium. The spores of four strains investigated reacted in the manner of subtilis spores, but showed greater variation in cell size and configuration of the nucleus (Pl. 5, figs. 30, 31).

\section{Synopsis of changes induced by differentiating procedures}

In reconstructing the sequence of events during differentiation it is helpful to postulate that the site of the spore's bright refractility, its imperviousness to stains and the scene of the first changes in differentiation is not the spore coat but a second, inner membrane surrounding the central body of cytoplasm and

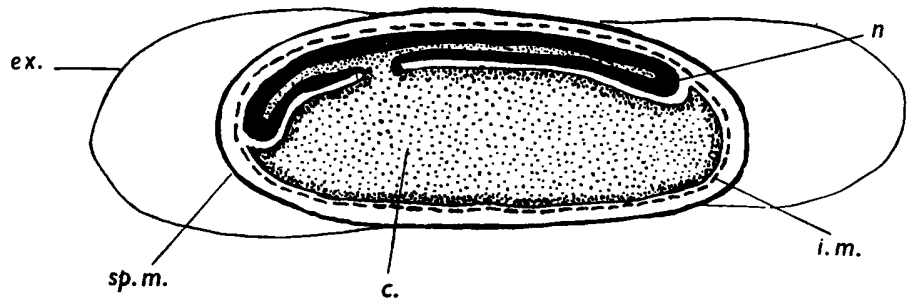

Fig. 4. Diagram of a hypothetical longitudinal section through a resting, untreated spore of $B$. cereus. The delicate 'exosporium' projects over the poles of the cell. Under the spore membrane proper (heavy, continuous line) there is a second membrane (broken line) surrounding both nucleus and cytoplasm. ex., exosporium; sp.m., spore membrane; i.m., inner membrane; $c$., cytoplasm; $n$., nucleus.

the nucleus. (In Metabacterium the spore coat often extends a little beyond the glistening spore body at the poles of the cell (Pl. 1, fig. 7), clearly indicating the separateness of the two structures.) The hypothetical membrane is represented by a broken line underneath the spore coat in Fig. 4. Earlier observations on the number of coats in the spore are discussed by Knaysi (1948).

Three steps in differentiation can be recognized:

(1) Inner and outer spore membranes are jointly lifted but not broken by the rounded nuclei of spores treated with acid mixtures in which chlorine water or hypochlorite have replaced permanganate (Pl. 1, figs. 1-3).

(2) When spores are differentiated by method $\mathbf{3}$ in the cold, the inner membrane is broken by the protruding nuclei, which consequently become stainable, while the cytoplasm, though shrunken, still retains its refractile and impervious coating (Fig. 3).

(3) Lastly, cytoplasm and nucleus, suffering changes of shape in the process, are both laid open to view and rendered stainable, following the complete breakdown of the inner spore membrane induced by methods 1,2 or 3 at room temperature (Pl. 2, fig. 8).

The forces which compel the striking changes of shape, and presumably of 
volume, of the spore nuclei, e.g. in differentiated subtilis spores, are not yet understood. It is difficult to resist the impression that the nuclei are under tension in the untreated cell, and are relieved from it when differentiating procedures weaken the constraining power of inner or outer spore membrane, or of both. The seeming contraction or collapse of the spore cytoplasm is probably accompanied by the breakdown of some cytoplasmic materials and the loss of substances through diffusion. Without this assumption it would be difficult to account for the difference between the intense basophilia and turgidity of the nearly mature but still directly stainable spore, and the shrunken moderately basophilic cytoplasm of spores differentiated by methods 1,2 or 3 .

\section{Observations on the nature of the differentiating process}

The most efficient differentiating reagents are oxidants. Thus, nitric acid is more effective than hydrochloric acid, and the potency of $\mathrm{N} / \mathbf{3}-\mathrm{HCl}$, which is almost inert at room temperature, is vastly increased by the addition of permanganate. It was found early in the work that spores killed, i.e. rendered unable to germinate, by flaming or by being boiled in water for $20 \mathrm{~min}$., no longer responded to differentiating treatments. They also fail to show, during subsequent incubation in a nutrient medium, the signs of abortive germination -loss of refractility and increased affinity for stains, followed by early disintegration-which are exhibited by spores killed in many other ways. The ability of spores 'killed' by some methods, to carry out the first few steps of germination indicates the temporary survival of some of the spore's normal metabolic systems. Boiling not only destroys these systems but also the spore's ability to respond to differentiation treatments. This observation raised the possibility that differentiation, like germination, may depend on the functioning of certain entities inside the spore, enzymes perhaps, conceived as heat-sensitive and susceptible to activation by certain chemicals.

To test this idea the effect of several enzyme poisons was investigated. It was found that differentiation was inhibited in the presence of approximately $0 \cdot 1-0.2 \mathrm{M}$ sodium fluoride. In $\mathrm{HCl}$-containing reagents $0.5 \%$ sodium fluoride caused nearly complete inhibition of differentiation and, if allowed to act for 3-5 min., also abolished the response to subsequent treatments with reagents not containing fluoride. A higher concentration of sodium fluoride $(1 \%)$ is required to achieve equally complete inhibition of differentiation in $\mathrm{N}-\mathrm{HNO}_{3}$. This effect, in contrast to the action of fluoride in $\mathrm{HCl}$-containing reagents, is largely reversible.

The course of differentiation in $\mathbf{0 . 1} \%$ potassium permanganate in $\mathrm{N} / 3-\mathbf{H C l}$ was followed quantitatively, with results which are summarized in Fig. 5 and Tables 1 and 2. After it had been allowed to 'ripen' for $\mathbf{3 0} \mathrm{min}$. on the bench this mixture caused the differentiation of $80-100 \%$ of cereus spores in 4-5 min. In Fig. 5 the proportion of differentiated spores is plotted against time spent in the reagent for four separate experiments. In a fifth experiment most of the spores briefly exposed to the $\mathrm{HCl}-\mathrm{KMnO}_{4}$ mixture not only failed, despite thorough washing, to germinate within $7 \mathrm{hr}$. when covered with heart infusion agar in the incubator, but also showed clear signs of degeneration. The spores 
in control samples, treated only with permanganate solution, germinated within $1 \mathrm{hr}$. Although most of the spores are rendered unable to germinate during the first 90 sec. in the reagent, few are visibly changed. That a reaction is started in the spores by the treatment is shown in the high proportion of

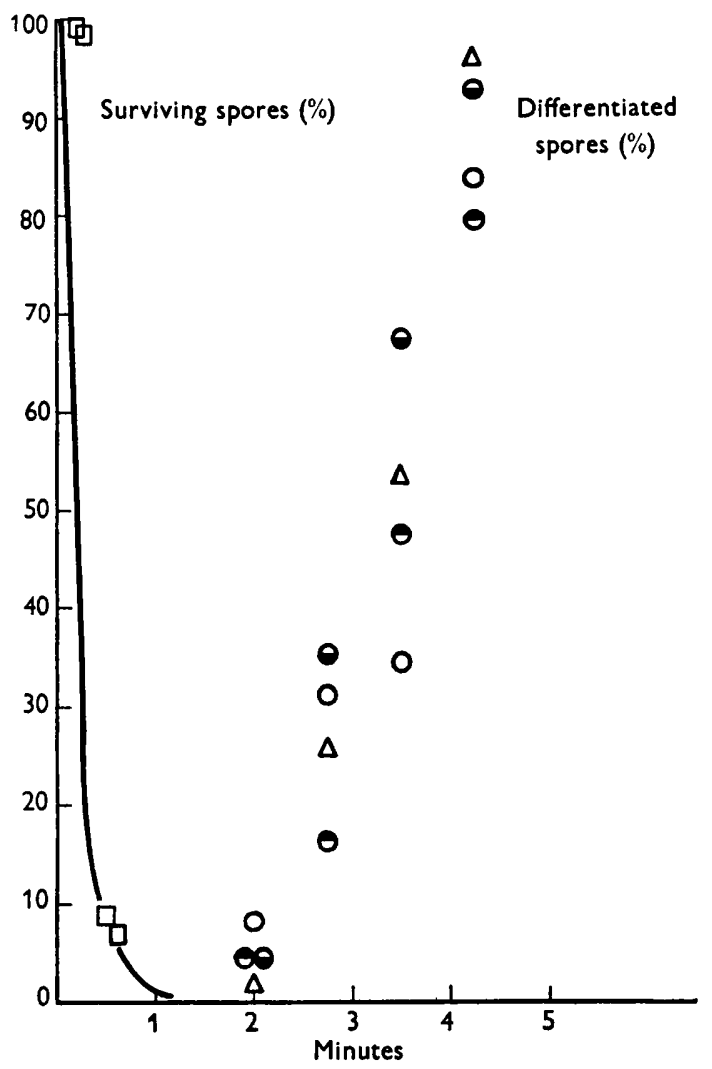

Fig. 5. Reaction of spores of $B$. cereus to $\mathrm{N} / 3-\mathrm{HCl}$ containing $0 \cdot 1 \%$ potassium permanganate. The curve on the left indicates the decrease in the number of viable spores effected by 45 and 90 sec. treatment with the differentiating reagent. The symbols on the right give the percentage of differentiated spores, in four experiments, as a function of the time spent in the reagent.

differentiated spores found when they are first treated for $2 \mathrm{~min}$. in the $\mathrm{HCl}-\mathrm{KMnO}_{4}$ mixture, then washed and immersed for another $3 \mathrm{~min}$. in N/3-HCl, a reagent which normally does not affect either the viability or the appearance of cereus spores.

Experiments with sodium fluoride present in the reagents during either the preliminary or the final treatment (Tables 1 and 2) have further clarified the course of differentiation and show that fluoride arrests this process in spores in which it has been started by preliminary exposure to a fluoride-free reagent.

It is concluded from these observations that the differentiation of cereus spores in $\mathrm{N} / 3-\mathrm{HCl}$ containing $0.1 \%$ permanganate is the result of two distinct 
reaction steps. The first step initiates differentiation but is not accompanied by visible changes in the structure of the spore; the second step leads to visual differentiation. Both steps are inhibited in the presence of $0.5 \%$ sodium fluoride, the second more completely than the first.

The fact that chlorine develops in the mixture of potassium permanganate with $\mathrm{HCl}$ suggested that chlorine might be a potent differentiating agent. The effect of water saturated with chlorine gas and of a commercial, approximately

Table 1. Effect of fluoride on the differentiation of cereus spores when present during the first 1.5 min. of exposure to a differentiating reagent

(Figures represent percentage of differentiated spores. A total of 2-300 was counted in every preparation in this experiment and the one described in Table 2.)

Treatment

(a) $1.5 \mathrm{~min}$. in $\mathrm{N} / \mathbf{3}-\mathrm{HCl}$ containing $0.1 \%$ potassium permanganate

(b) Treatment as in (a) followed by $3 \mathrm{~min}$. in $\mathrm{N} / 3-\mathbf{H C l}$

(c) $1.5 \mathrm{~min}$. in $\mathrm{N} / 3-\mathrm{HCl}$ containing $0.1 \%$ $\mathrm{KMnO}_{4}$ and $0.5 \% \mathrm{NaF}$

(d) Treatment as in (c) followed by $3 \mathrm{~min}$. in $\mathrm{N} / 3-\mathrm{HCl}$
Differentiated spores (\%)

$\mathbf{3} \cdot \mathbf{7}$

$\mathbf{2} \cdot \mathbf{0}$

$98 \cdot 5$

98.5

$<1$

$<1$

$47 \cdot 0$

43.0

Table 2. Complete inhibition of differentiation when fluoride is present during the last $3 \mathrm{~min}$. of the exposure of cereus spores to a differentiating reagent

Treatment

(a) $1.5 \mathrm{~min}$. in $\mathrm{N} / 3-\mathrm{HCl}$ containing $0.1 \%$ $\mathrm{KMnO}_{4}$

(b) Treatment as in (a) followed by $3 \mathrm{~min}$. in $\mathbf{N} / \mathbf{3}-\mathbf{H C l}$

(c) Treatment as in (a), followed by $3 \mathrm{~min}$. in $\mathrm{N} / 3-\mathrm{HCl}$ containing $0.5 \% \mathrm{NaF}$

(d) $3 \mathrm{~min}$. in $\mathrm{N} / 3-\mathrm{HCl}$, without pre-treatment
Differentiated spores (\%)

$22 \cdot 6$

$96 \cdot 0$

$92 \cdot 6$

$\mathbf{1 6 \cdot 5}$

$22 \cdot 5$

$15 \cdot 5$

$<\mathbf{1}$

$<1$

1.5 M solution of sodium hypochlorite ('Javex'; Standard Chemical Company, Toronto) on spores was studied and, provided very low concentrations were employed and the reagents dissolved in 0.33-1.0 N-HCl, differentiation of spores was consistently obtained. One part of chlorine water in 30 parts of $\mathrm{N} / \mathbf{3}-\mathrm{HCl}$ caused $50-80 \%$ differentiation in $5 \mathrm{~min}$. at room temperature; higher concentrations were ineffective; without $\mathrm{HCl}$ there is no effect. Similarly, I vol. of 'Javex' solution +100 vol. of $\mathrm{N} / 3-\mathrm{HCl}$ caused $20 \%$ differentiation in 5 min. Spores when treated with higher than optimal concentrations of the chlorine reagents in $\mathrm{N} / 3-\mathrm{HCl}$ appeared brightly refractile and nearly as impervious to stains as normal spores, though the shape of many of them was no longer symmetrical. A distinct hump (Pl. 1, figs. 1-3) arose on the side of the cell, 
corresponding in size and position to the protruding nucleus of spores differentiated by methods 2 or 3.

The failure of hypochlorite in concentrations above $c .0 .03 \mathrm{M}$ to cause differentiation, might indicate that the spores are killed by too high a concentration of the reagent before differentiation can begin. If this were true, spores killed with hypochlorite in acid solution should also fail to respond to other differentiating treatments; this was found to be so. Neither by methods 1,2 or 3 was it possible to induce the differentiation of spores previously treated with 1 vol. 'Javex' +9 vol. $\mathrm{N} / 3-\mathrm{HCl}$. But the poisoned spores themselves were able to carry out this reaction. One hour after chlorine-poisoned spores had been incubated in a moist chamber.under a slab of heart infusion agar, all had become stainable and showed peripheral nuclei protruding from a strongly basophilic central body of cytoplasm. No further development was observed. The experiment has been repeated several times with the same result.

A somewhat similar behaviour, though not leading to proper differentiation, is shown by spores poisoned by $\mathbf{0 . 1} \mathrm{M}$ fluoride in mixtures of permanganate with $\mathrm{HCl}$. Although refractory to differentiating treatments, the poisoned spores, when incubated with heart infusion agar, lost their refractility, became diffusely stainable and eventually disintegrated.

These two observations also point to the possibility that the spore's own chemical activity may be an important part of its response to differentiating treatments.

\section{DISCUSSION}

The refractile, not directly stainable spores whose structure has been described in the preceding pages represent the normal, heat-resistant and viable resting stage of Bacillus cells. Non-refractile and directly stainable 'spores' which have been described from time to time, most recently by Delaporte (1950) for $B$. mycoides, may safely be regarded as the result of premature and incomplete germination. A special type of spore with 'transparent central regions' which Knaysi, Baker \& Hillier (1947) have recorded with the electron microscope are found in many Bacillus species and have long been known. Examination with the light microscope and slide cultures leave no doubt that these objects are the lifeless remains of autolysed spores.

The structure of the spore cannot be satisfactorily discussed without regard to its development. Knaysi \& Baker (1947), relying on the electron microscope, described variously shaped masses of relatively high density in Bacillus cells 'grown in a nitrogen-free medium' and have interpreted these alternately as division figures of vegetative nuclei or as developing multi-nucleate spores. In view of the abnormal nature of their material, the unspecific character of the information from electron microscopy and the absence of supplementary documentation based on light-microscopy and conventional cytological methods, it is difficult to assess the significance of these findings.

Cytological aspects of spore formation have lately been described by Klieneberger-Nobel (1945), Flewett (1948), Bisset (1950), and others, who are agreed that the spore arises in the cytoplasm in connexion with one of several 
nuclear elements present in the sporulating bacillus. As it increases in size the spore becomes increasingly basophilic. Its affinity for stains at this stage differs from that of the cytoplasm of growing bacteria in that it resists hydrolysis with $\mathrm{N}-\mathrm{HCl}$ at $60^{\circ}$. This makes it difficult to trace the configuration of the nuclear element inside the developing spore. In the most advanced developmental stage that still yields to hydrolysis it has the shape of a ring or ellipse according to Flewett (1948), an observation that needs to be reconciled with Knaysi's statement (1946) that immature spores give a diffuse Feulgen reaction. Flewett believes that the ring gradually expands until it reaches the periphery of the cell.

The peripheral chromatinic structure in Bacillus spores is visible unstained, after differentiation, as a well-defined body by the side of the cytoplasm. It has been referred to as the nucleus because its division during germination gives rise to the chromatinic, presumably nuclear, structures of the vegetative cell (Robinow 1942, 1945; Delaporte, 1950). Its affinity for basic stains and its positive Feulgen reaction, as well as its destruction by trypsin and depletion by deoxyribonuclease, are in accord with this interpretation.

The accumulated evidence indicates that at least two distinct structures are contained in the spore: nucleus and cytoplasm; but we are still faced with the problem of their relative arrangement in the untreated cell. Certainty on this point could only be derived from the examination of sections cut from spores, but this has not been attempted. Spores having the structure here described are not without precedent, for peripheral, rod- or disk-shaped nuclei can be demonstrated without recourse to differentiating methods in the spores of a (bacterial?) parasite of some species of Trichonympha (Kirby, 1944).

It is obvious that the appearance of cereus spores, differentiated with permanganate mixtures at room temperature is an artefact. But the picture of a flat nucleus, moulded to a turgid central body, consistently encountered in films of spores differentiated with $\mathrm{N}-\mathrm{HNO}_{3}$ in the cold, probably comes reasonably close to the natural condition of nucleus and cytoplasm in the spore-cell. In spores differentiated with permanganate+acid mixtures the situation is probably complicated by the nucleus drawing some of the cytoplasm up into itself as it rises above the cell surface (Fig. 1b).

The spore loses its refractility and becomes stainable in the course of both differentiation and germination: phenomena believed to involve a profound change of the properties of the shiny, inner, spore membrane. There ends the similarity between the two processes. When the spore becomes directly stainable in the course of germination the nucleus has already left its peripheral position and has sunk into the cytoplasm (Robinow, 1945). At the same time the germinating cell as a whole no longer reacts with shrinkage and collapse to differentiating reagents (in B. cereus, $50 \%$ of the spores are thus transformed within the first 5 min. in heart infusion broth at $37^{\circ}$ ). In other words, when treated with differentiating reagents, spores in the very earliest stages of germination reveal neither bulging nuclei, nor shrunken central bodies of cytoplasm. It would be interesting to know why it is that resting spores, so resistant to most noxious influences, react violently to reagents which have no 
visible effect on the structure of the vegetative phase; but the cytological picture does not shed much light on this paradoxical situation.

In the present study the huge spores of Metabacterium have served as largescale models of the condition assumed by differentiated cereus spores. This comparison is useful though there is little evidence as yet that the mushroomlike structure in Metabacterium spores shares all the properties of its counterpart in cereus spores. The results of the Feulgen test have been erratic and germination could not be observed, neither has the study of the formation of Metabacterium spores proved helpful in this respect. On the other hand, the similarity in the construction of the spores of the two species is so great that one can hardly ignore it. Gain from the comparison has not been one-sided. The taxonomic position of Metabacterium has long been a matter of doubt. By the organization of its spores, its lively motility (overlooked by the first observers) by means of peritrichous flagella and the occasional occurrence of individuals in a state suggesting binary fission, the organism now proclaims itself a true bacterium.

Constant in its organization, easily obtained, handled and processed, the spore provides a useful starting-point for the study of bacterial cytology. Progress in the biology of this enigmatic cell now depends on the chemical characterization of the structures established by morphological studies.

The author is indebted to Prof. R. G. E. Murray for his interest in all phases of the work and many helpful suggestions. He also wishes to thank Dr F. H. Johnson, of the Biology Department, Princeton University, for the hospitality of his laboratory where some of the work was done. Thanks are due to Dr James Hillier of the R.C.A. Laboratories, Princeton, U.S.A., and Dr C. G. Hedén of the Karolinska Institute, Stockholm, for giving of their time and skill in taking electron micrographs of some of the writer's specimens.

\section{REFERENCES}

Bisset, K. A. (1950). The sporulation of Clostridium tetani. J. gen. Microbiol. 4, 1. Chatron, E. \& Pérard, C. (1913). Schizophytes du caecum du cobaye. II. Metabacterium polyspora n.g., n.sp. C.R. Soc. Biol., Paris, 74, 1232.

Delaporte, Berthe (1939-40). Recherches cytologiques sur les bactéries et les cyanophycées. Rev. gén. Bot. 51, 615, 689, 748; 52, 112.

Delaporte, Berthe (1950). Observations on the cytology of bacteria. Advanc. Genet. 3, 1. New York, N.Y.: Academic Press.

Dooren DE Jong, L. E. DEN (1933). Utber Bacillus mycoides und den Pleomorphismus. Arch. Mikrobiol. 4, 36.

FlewetT, T. H. (1948). Nuclear changes in Bacillus anthracis and their relation to variants. J. gen. Microbiol. 2, 325.

KIRBX, H. (1944). The structural characteristics and nuclear parasites of some species of Trychonympha in termites. Univ. Calif. Publ. Zool. 49, 185.

Kuteneberger-Nobel, E. (1945). Changes in the nuclear structure of bacteria, particularly during spore formation. J. Hyg., Camb., 44, 99.

KNAYSI, G. (1946). Further observations on the nuclear material of the bacterial cell. J. Bact. 51, 177.

KNAYSI, G. (1948). The endospore of bacteria. Bact. Rev. 12, 19.

KNAYSi, G. \& BaKer, R. F. (1947). Demonstration, with the electron microscope, of a nucleus in Bacillus mycoides grown in a nitrogen-free medium. J. Bact. 53, 539. 
KNaysi, G., Baker, R. F. \& Hillier, J. (1947). A study, with the high-voltage electron microscope, of the life cycle and structure of the endospore in Bacillus mycoides. J. Bact. 53, 525.

Kroenig, B. \& Paul, T. (1897). Die chemischen Grundlagen der Lehre von der Giftwirkung und Diesinfektion. Z. Hyg. InfektKr. 25, 1.

LEwIS, I. M. (1934). Cell inclusions and endospore formation in Bacillus mycoides. J. Bact. 28, 133.

McGaughey, C. A. \& Chu, H. P. (1948). The egg yolk reaction of aerobic sporing bacilli. J. gen. Microbiol. 2, 334.

Mrlovidov, P. (1935). Ergebnisse der Nuklealfärbung bei den Myxobakterien und einigen anderen Bakterien. Arch. Mikrobiol. 6, 475.

Piekarski, G. (1937). Cytologische Untersuchungen an Paratyphus- und Colibakterien. Arch. Mikrobiol. 8, 428.

Piekarski, G. (1940). Über kernähnliche Strukturen bei Bacillus mycoides Flügge. Arch. Mikrobiol. 11, 406.

Robinow, C. F. (1942). A study of the nuclear apparatus of bacteria. Proc. roy. Soc. B, 130, 299.

Robinow, C. F. (1945). 'Addendum' to The Bacterial Cell, by R. J. Dubos. Cambridge, Mass. : Harvard University Press.

Stille, B. (1937). Zytologische Untersuchungen an Bakterien mit Hilfe der Feulgenschen Nucleal Reaktion. Arch. Mikrobiol. 8, 125.

\section{EXPLANATION OF PLATES}

\section{Plate 1}

The magnification is the same for all photographs on this plate and is indicated by the scale next to fig. 5 .

Figs. 1-3. Spores of $B$. cereus treated for 5 min. with 1 vol. 'Javex' hypochlorite solution in $10 \mathrm{vol}$. $\mathrm{N} / 3-\mathrm{HCl}$ at room temperature. Stained with crystal violet. A delicate, boatshaped envelope is protruding over the poles of most of the spores. In some of the spores the nucleus has suffered a change of shape underneath the unbroken spore membrane and is raising a hump in the contours of the cell.

Fig. 4. Spores of $B$. cereus after $20 \mathrm{~min}$. in $\mathrm{N}-\mathrm{HNO}_{3}$ at room temperature. Stained with crystal violet.

Figs. 5, 6. A group of spores from the same preparation that provided fig. 4, photographed at two different levels of focus. In fig. 5 the nucleus of the spore marked with a cross is just visible bending around the left end of the cell. In fig. 6 it is seen from the surface as a dark shield covering the greater part of the cytoplasm.

Fig. 7. One of two spores in an individual of Metabacterium polyspora photographed at the same magnification as the other figures on this plate. Compare with fig. 1.

\section{Plate 2}

The magnification of the photographs in this plate is indicated by the scale beneath fig. 8 . In the photographs the spore membrane, owing to imperfect optical resolution, appears relatively broad, as if drawn with a soft pencil. In electron-micrographs of cereus and subtilis spores the membrane is revealed as a very thin structure, lacking the double contours it seems to possess in light-optical pictures.

Figs. 8-10. Spores of $B$. cereus treated for 5 min. at room temperature, with $\mathrm{N} / 3-\mathrm{HNO}_{3}$ containing $0.1 \% \mathrm{KMnO}_{4}$. Stained with crystal violet. Note surface aspect of the nucleus in the spore marked with a cross.

Figs. $11 a, b ; 12 a, b$; and $13 a, b$. The (a) pictures of the three pairs of photographs represent a group of living, resting spores lightly stained with crystal violet. The $(b)$ pictures show the changed appearance of the same group of spores after treatment with $\mathrm{N} / 3-\mathrm{HNO}_{3}$, containing $0.1 \%$ potassium permanganate, for $10 \mathrm{~min}$. at room temperature, followed by staining with crystal violet. The protruding nuclei in the $(b)$ pictures contrast with the flat, clinging nuclei of fig. 9 on this plate and Pl. 1, fig. 4. Note that the shape of the spores is not altered and their size but slightly decreased by the treatment. 
Plate 3

Magnification of the photographs in the upper half of this picture is the same as that of the figures in the two previous plates and is indicated by a scale beneath fig. 15. The much higher magnification of the electron-micrographs in the lower half of the plate is indicated by the scale underneath fig. 17. These photographs were made by Dr J. Hillier of the R.C.A. Laboratories, Princeton, New Jersey.

Fig. 14a, $b$. Two pictures of a pair of Metabacterium spores $(a)$ before and $(b)$ after differentiation with $\mathrm{N}-\mathrm{HNO}_{3}$. Both stained with crystal violet. In the spore on the left the mushroom-like peripheral body which differentiation reveals in these spores is seen from above, hence its ellipsoidal appearance.

Fig. 15. Two individuals of Metabacterium with two spores in each. Stained with crystal violet after differentiation with $\mathrm{HNO}_{3}$.

Fig. 16. A group of cereus spores, including a few differentiated ones, shown for comparison with the spores of Metabacterium.

Figs. 17, 18. Electron-micrographs of resting spores of $B$. cereus. The delicate, much folded, outer envelope of the spores is clearly visible. This envelope is external to the spore membrane proper.

Figs. 19, 20. Electron-micrographs of cereus spores, differentiated by method 3, washed and dried. The tenuous outer spore envelope not as clearly visible as in the untreated spores. The spore membrane proper is wrinkled. The nucleus is seen projecting above the cell surface as a dark body with smooth contours. Compare with Fig. $1 b$.

\section{Plate 4}

The magnification of the photographs on this plate is indicated by a scale beneath fig. 23.

Figs. 21-23. Feulgen reaction of the spores of $B$. cereus after a few hours in Schiff's reagent. Photographed mounted in water, without counterstaining.

Figs. 24, 25. Spores of $B$. cereus fixed with osmium tetroxide vapour, hydrolysed with $\mathrm{N}-\mathrm{HCl}$ at $60^{\circ}$ and stained with Giemsa solution. Compare with Pl. 1, figs. 4, 5, and with Pl. 2, figs. 8, 9, 10, $11 b$ and $12 b$. Note indistinct cytoplasm and transparent nuclei. In several spores the nuclei appear broken up into granules.

Fig. 26. Spores of $B$. cereus differentiated by method 3 , stained with crystal violet and photographed in red light from a Wratten $\mathbf{F} 29$ filter. Note that nuclei and cytoplasms appear more transparent than in the photographs on $\mathrm{Pl} .2$.

Fig. 27. Spores of $B$. cereus differentiated with $\mathrm{N}-\mathrm{HNO}_{3}$ and then treated with trypsin. The nuclei have been more or less completely destroyed. The cytoplasm has contracted. Stained with crystal violet.

\section{Plate 5. B. subtilis and B. megatherium}

The magnification of the photographs on this plate is indicated by the scale beside fig. 30 .

Figs. 28, 29. Two groups of spores of $B$. subtilis from a preparation that had been treated for 10 min. at room temperature with $\mathrm{N}-\mathrm{HNO}_{3}$ and was then stained with Giemsa solution. Compare these pictures with electron micrographs of treated and untreated spores of the same culture on $\mathrm{Pl} .6$.

Fig. 30. Spores of $B$. megatherium stained with crystal violet. Note a few deeply stained (prematurely germinated?) cells.

Fig. 31. Spores of B. megatherium treated for $10 \mathrm{~min}$. with $\mathrm{N}-\mathrm{HNO}_{3}$ at room temperature. Very large nuclei are protruding from the cell surface, indicating considerable rearrangement of the spore contents. Giemsa stain.

\section{Plate 6}

The magnification of the photographs on this plate is indicated by the scale beneath fig. 33 .

Electron-micrographs of spores of the same culture of $B$. subtilis which provided figs. 28 and 29. The photographs on this plate were made by Dr C. G. Heden in the Cell Research Laboratory of the Karolinska Institute, Stockholm, from specimens prepared by the writer in London, Canada. 
Journal of General Microbiology, Vol. 5, No. 3
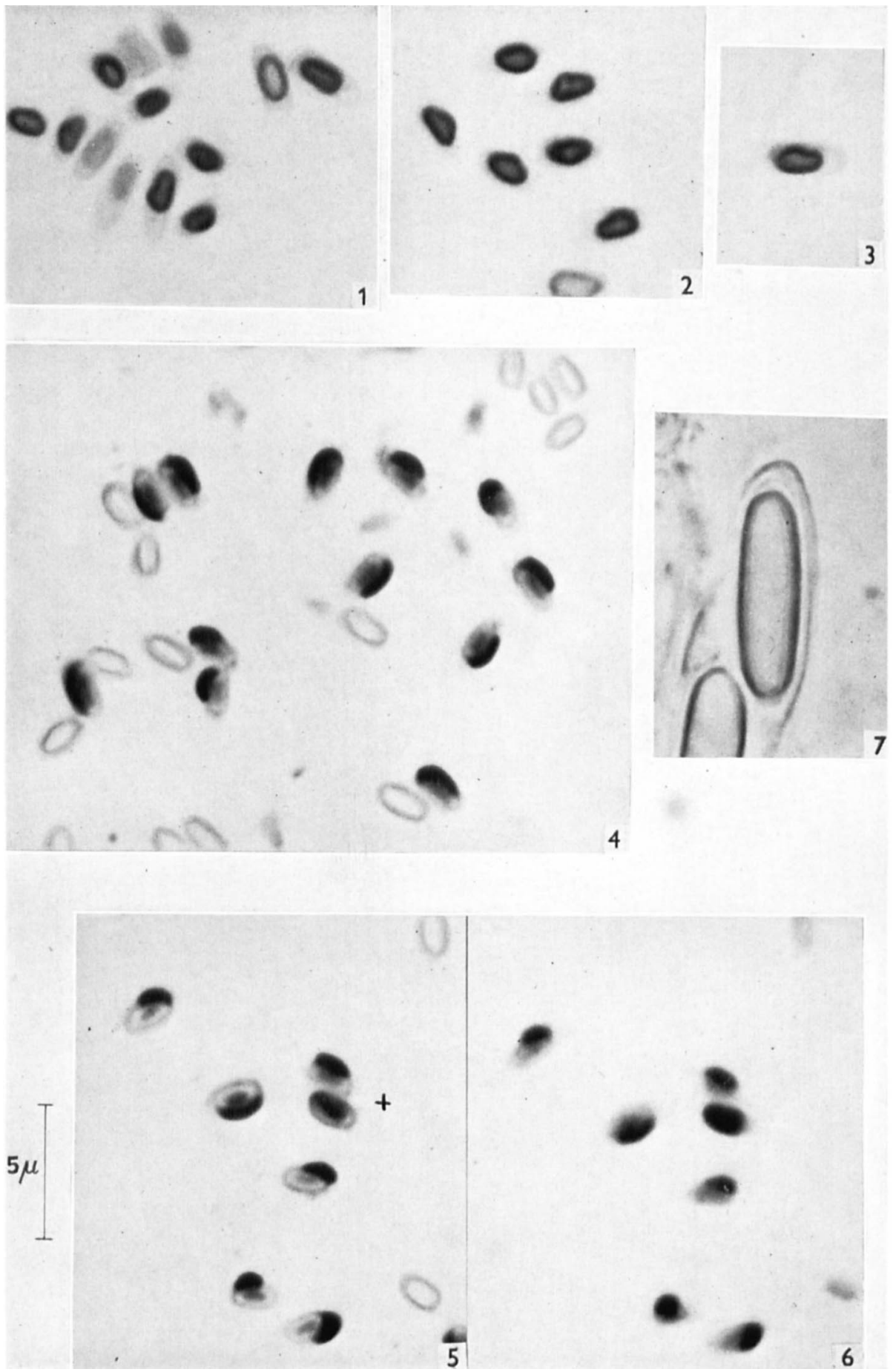

Fig. 1-7

C. F. Robinow-Structure of spores. Plate 1 
Journal of General Microbiology, Vol. 5, No. 3

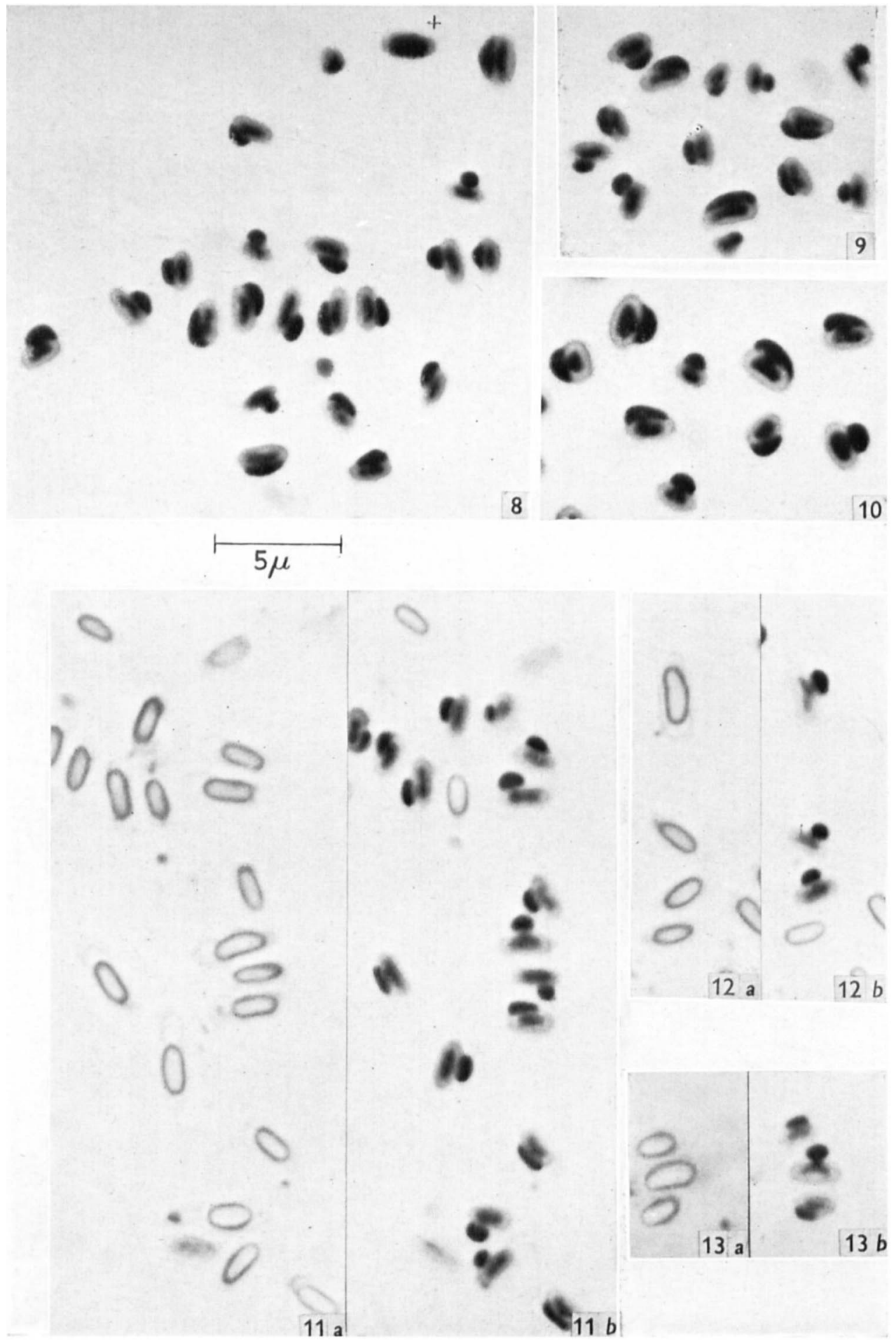

Fig. 8-13

C. F. Robinow-Structure of spores. Plate 2 
Journal of General Microbiology, Vol. 5, No. 3
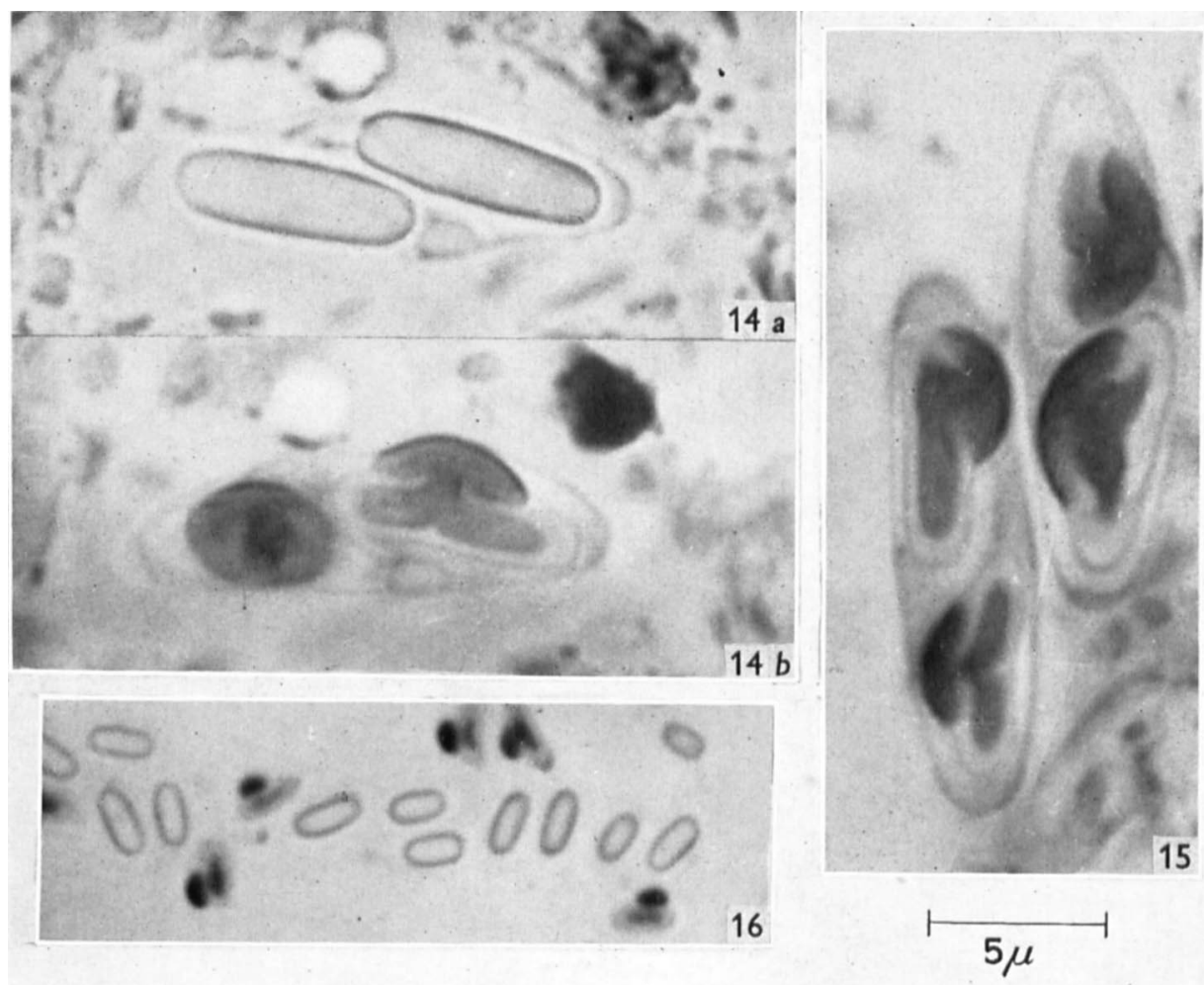

5
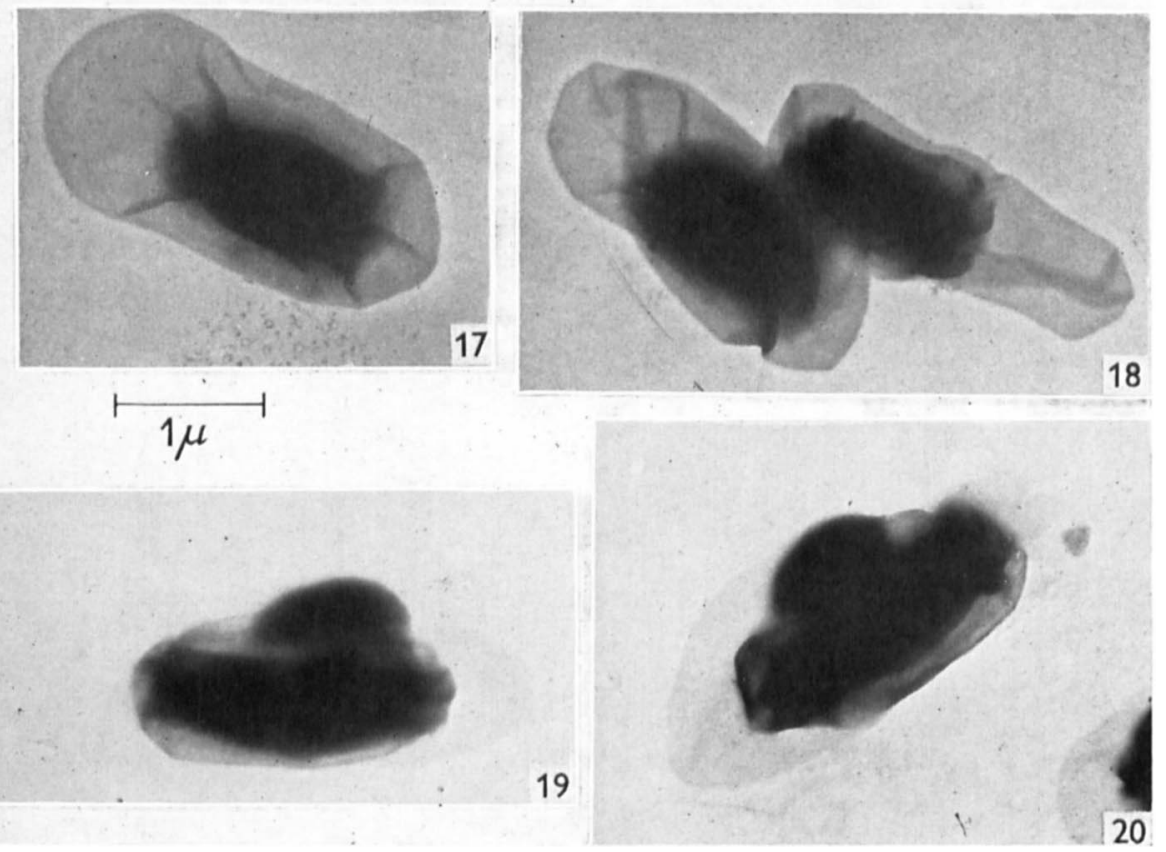

Figs. 14-20

C. F. Robinow-Structure of spores. Plate 3 
Journal of General Microbiology, Vol. 5, No. 3

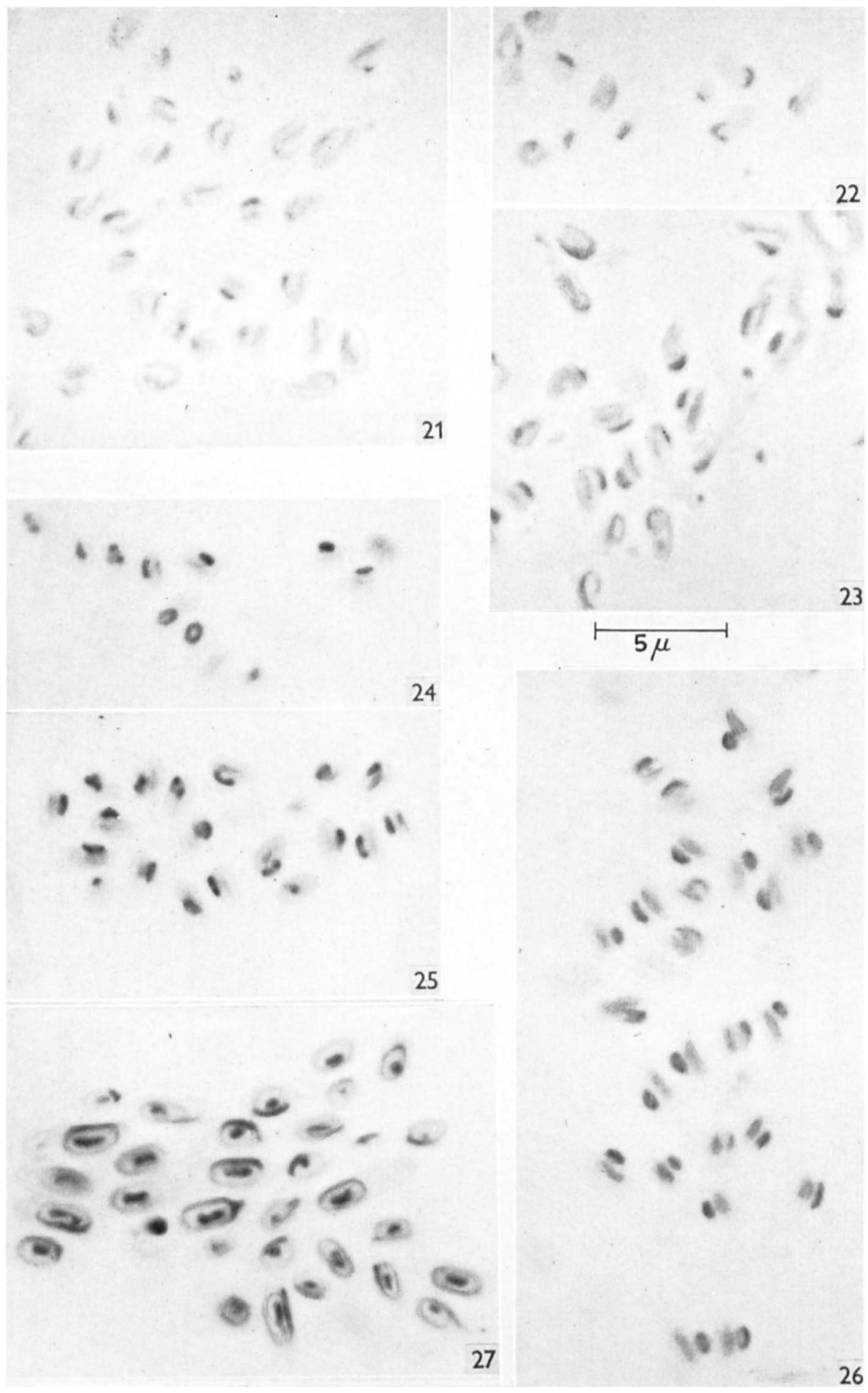

Figs. 21-27

C. F. Robinow-Structure of spores. Plate 4 
Journal of General Microbiology, Vol. 5, No. 3
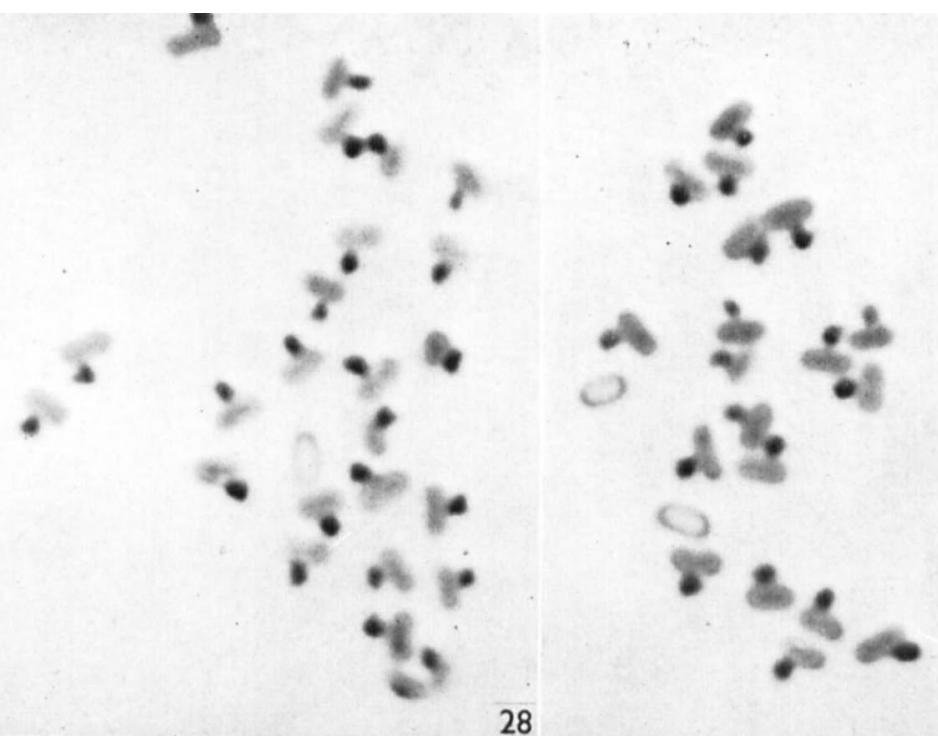

28
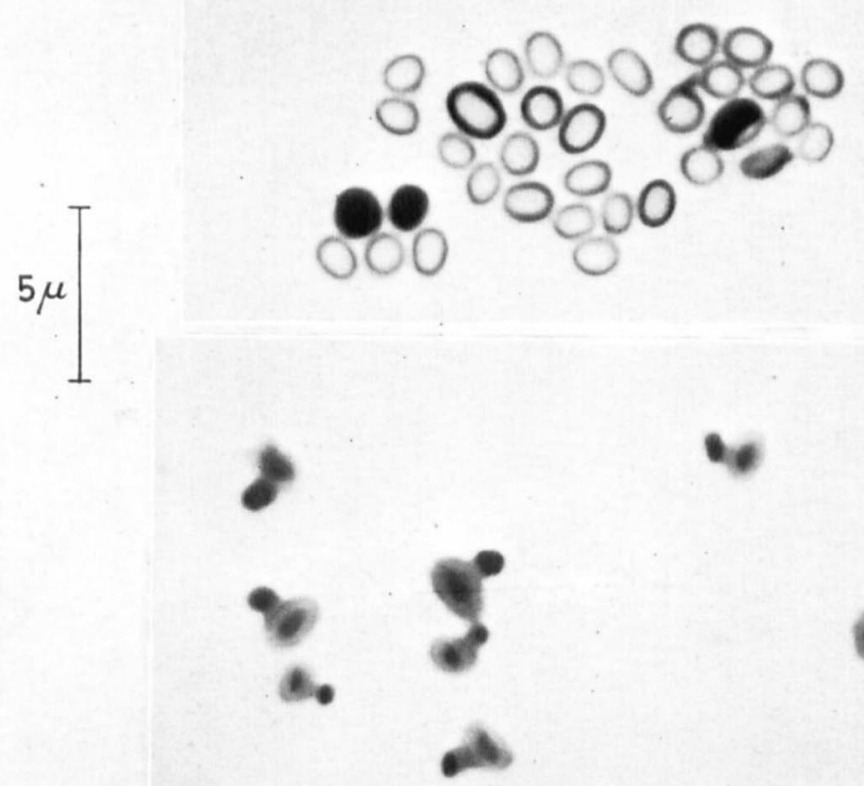

Figs. 28-31

C. F. Robinow-Structure of spores. Plate 5 
Journal of General Microbiology, Vol. 5, No. 3
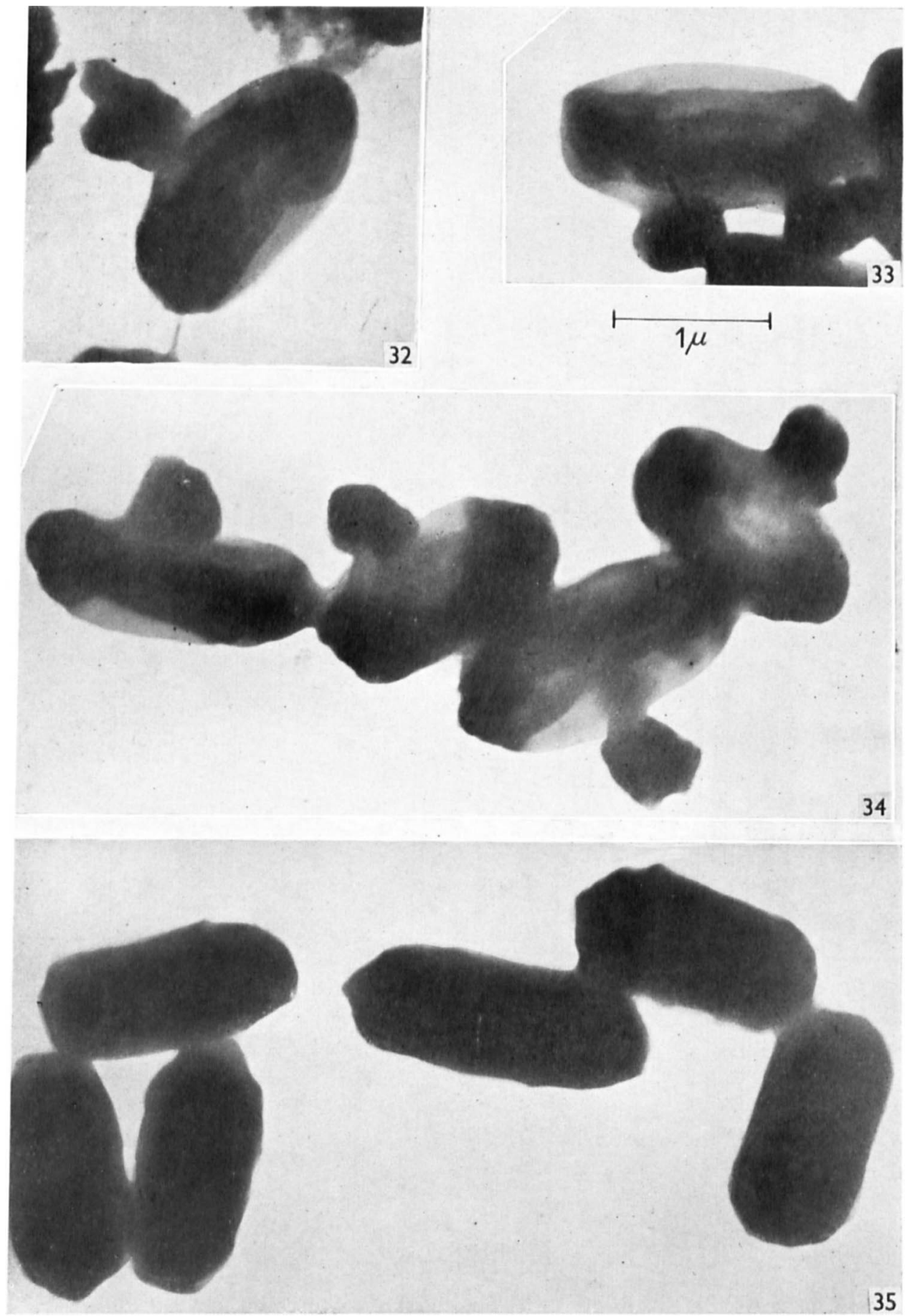

Figs. 32-35

C. F. Robinow-Structure of spores. Plate 6 
Figs. 32-34. Spores from the same culture as those in fig. 28 treated for 20 min. with $\mathrm{N}-\mathrm{HNO}_{3}$ at room temperature, washed and dried. Note compact, angular nuclei, shrunken cytoplasm and delicate spore membrane. The ratio of nuclear volume to volume of the rest of the spore seems larger in light-optical pictures than in electron-micrographs. This is perhaps because the spores have to be dried for electron microscopy whereas they are mounted wet and are also imperfectly resolved in light-optical specimens.

Fig. 35. Untreated, resting spores of $B$. subtilis, washed and dried.

(Received 19 September 1950) 